\title{
Planning Implementation Success of Syncope Clinical Practice Guidelines in the Emergency Department Using CFIR Framework
}

\author{
Jing Li ${ }^{1,2, *(\mathbb{D})}$, Susan S. Smyth ${ }^{2}$, Jessica M. Clouser ${ }^{1}$, Colleen A. McMullen ${ }^{2}\left(\mathbb{D}\right.$, Vedant Gupta ${ }^{2}$ (D) \\ and Mark V. Williams ${ }^{1}(\mathbb{D}$ \\ 1 Center for Health Services Research, University of Kentucky, Waller Health Care Annex, 304A, \\ Lexington, KY 40536, USA; jess.clouser@uky.edu (J.M.C.); mark.will@uky.edu (M.V.W.) \\ 2 Department of Cardiovascular Medicine, Gill Heart \& Vascular Institute, University of Kentucky, \\ 900 S. Limestone St., CTW320, Lexington, KY 40536, USA; susansmyth@uky.edu (S.S.S.); \\ cmcmu2@uky.edu (C.A.M.); vedant.gupta@uky.edu (V.G.) \\ * Correspondence: jingli.tj@uky.edu; Tel.: +1-859-218-1038
}

\section{check for} updates

Citation: Li, J.; Smyth, S.S.; Clouser, J.M.; McMullen, C.A.; Gupta, V.; Williams, M.V. Planning Implementation Success of Syncope Clinical Practice Guidelines in the Emergency Department Using CFIR Framework. Medicina 2021, 57, 570. https://doi.org/10.3390/medicina 57060570

Academic Editors: Franca Dipaola, Monica Solbiati and Emanuele Pivetta

Received: 25 March 2021

Accepted: 1 June 2021

Published: 3 June 2021

Publisher's Note: MDPI stays neutral with regard to jurisdictional claims in published maps and institutional affiliations.

Copyright: (C) 2021 by the authors Licensee MDPI, Basel, Switzerland. This article is an open access article distributed under the terms and conditions of the Creative Commons Attribution (CC BY) license (https:// creativecommons.org/licenses/by/ $4.0 /)$.

\begin{abstract}
Background and Objectives: Overuse and inappropriate use of testing and hospital admission are common in syncope evaluation and management. Though guidelines are available to optimize syncope care, research indicates that current clinical guidelines have not significantly impacted resource utilization surrounding emergency department (ED) evaluation of syncope. Matching implementation strategies to barriers and facilitators and tailoring strategies to local context hold significant promise for a successful implementation of clinical practice guidelines (CPG). Our team applied implementation science principles to develop a stakeholder-based implementation strategy. Methods and Materials: We partnered with patients, family caregivers, frontline clinicians and staff, and health system administrators at four health systems to conduct quantitative surveys and qualitative interviews for context assessment. The identification of implementation strategies was done by applying the CFIR-ERIC Implementation Strategy Matching Tool and soliciting stakeholders' inputs. We then co-designed with patients and frontline teams, and developed and tested specific strategies. Results: A total of 114 clinicians completed surveys and 32 clinicians and stakeholders participated in interviews. Results from the surveys and interviews indicated low awareness of syncope guidelines, communication challenges with patients, lack of CPG protocol integration into ED workflows, and organizational process to change as major barriers to CPG implementation. Thirty-one patients and their family caregivers participated in interviews and expressed their expectations: clarity regarding their diagnosis, context surrounding care plan and diagnostic testing, and a desire to feel cared about. Identifying change methods to address the clinician barriers and patients and family caregivers expectations informed development of the multilevel, multicomponent implementation strategy, MISSION, which includes patient educational materials, mentored implementation, academic detailing, Syncope Optimal Care Pathway and a corresponding mobile app, and Lean quality improvement methods. The pilot of MISSION demonstrated feasibility, acceptability and initial success on appropriate testing. Conclusions: Effective multifaceted implementation strategies that target individuals, teams, and healthcare systems can be employed to plan successful implementation and promote adherence to syncope CPGs.
\end{abstract}

Keywords: syncope; emergency department; diagnosis; risk stratification

\section{Introduction}

Syncope is a common yet complex presenting symptom and requires thoughtful and efficient evaluation to determine its etiology. Estimates indicate that one-half of all Americans will experience loss of consciousness during their lives, with recurrence rates as high as $13.5 \%$ [1]. The incidence of syncope is roughly bimodal, with a peak in late 
adolescence to early adulthood, typically vasovagal in origin [2], and a second peak in older age, with a sharp rise after age 70 years [3]. Approximately $1 \%$ to $3 \%$ of all emergency department (ED) visits, as many as atrial fibrillation, and up to $6 \%$ of all hospital admissions are due to syncope $[1,4,5]$. Though vasovagal reflex-mediated syncope and orthostatic hypotension are the two most common types with benign courses [6], a cardiac etiology of syncope is associated with significantly higher rates of morbidity and mortality [3].

Patients who present to the ED tend to be older and are more likely to have a cardiac etiology [7]. Notably, experiencing syncope affects patients' quality of life (QoL), and those with more frequent syncope report overall lower physical and mental health and impairment in activities of daily living [8-13]. The QoL among patients with recurrent syncope appears equivalent to those with severe rheumatoid arthritis or chronic lower back pain [10]. Recurrent syncope can also lead to long-term facility stay and a devastating loss of independence [14]. In addition to the negative effects on QoL, syncope also has an economic impact. The U.S. Healthcare Utilization Project has estimated total annual hospital costs of greater than $\$ 4.1$ billion in 2014 dollars with a mean cost of $\$ 9400$ per admission [15]. One 2017 article showed that, after adjusting for inflation, the median hospital charge for a single admission for syncope increased by 1.5 times from the preceding decade [16].

Due to concerns that patients presenting with syncope are at risk for an impending catastrophic event, overuse and inappropriate use of testing and hospital admission are common [17-20]. Indisputably, among patients who present with syncope, clinicians must identify those at high risk of adverse outcomes. Nonetheless, the majority are at low risk. To assist clinicians in assessing patient risk, several syncope risk stratification calculators have been developed over the last 20 years; however, one study found that the concordance between different risk scores was only moderate and the application of both decision rules and clinical judgement may lead to some clinical benefit [21]. A body of literature documents under-utilization of efficient tests, over-utilization of unnecessary tests, excess rates of admissions with limited diagnostic or therapeutic yield, over-expenditure associated with syncope management, and heightened risk to patients due to unnecessary tests and hospitalizations, including iatrogenic harms such as medication errors and in-hospital delirium [17-19,22]. Given the frequency of syncope as a symptom, the cumulative cost and burden to the healthcare system and patients is substantial.

Aiming to provide guidance on optimizing the evaluation and management of syncope, a collaboration of the American College of Emergency Physicians, Society for Academic Emergency Medicine, American College of Cardiology (ACC), American Heart Association (AHA) and Heart Rhythm Society (HRS) issued a Guideline for the Evaluation and Management of Patients With Syncope in 2017 [15]. The 2017 Syncope Guideline represents an effort to standardize clinical practice and reduce unnecessary services. However, the mere existence of a guideline does not guarantee effective use. Evidence shows that the development of clinical guidelines alone is often not sufficient, even if recommendations in the guideline have been demonstrated to be effective on the structure, process and/or outcomes of patient care [23-27]. Indeed, one recent study suggested that the current clinical guidelines have not significantly impacted resource utilization surrounding ED evaluation of syncope, and novel strategies are keenly needed to change ED practice patterns for such patients [28]. Matching implementation strategies to barriers and facilitators for the use of the syncope guideline and tailoring strategies to local context hold significant promise for a successful implementation [29-31]. However, evidence on effective implementation strategies for syncope care in the ED is scarce. Project MISSION, leveraging an engaged interdisciplinary team, aimed to facilitate the efficient and systematic implementation of high-value care to patients presenting to an ED with syncope. Our study team applied implementation science to develop and test a stakeholder-based implementation strategy, MISSION (Multicomponent, Multilevel Implementation Strategy for Syncope Optimal Care Through Engagement). 


\section{Materials and Methods}

\subsection{Study Setting and Participants}

To maximize the probability that the implementation strategy will be valuable for widespread adoption and scale-up in different ED settings, Project MISSION included a diverse group of health systems and hospitals: an academic medical center (AMC); an urban faith-based community health system; a not-for-profit health system serving a predominantly rural Appalachian population; and a community teaching hospital in a suburb. At each facility, the target participants included emergency medicine (EM), hospital medicine (HM), and cardiology clinicians and stakeholders (e.g., primary care provider, nurse manager, diagnostic test/procedure manager). Patients and family caregivers were recruited for interview from the AMC.

\subsection{Study Framework}

The Consolidated Framework of Implementation Research (CFIR) [32] is commonly used to guide the design, implementation and evaluation of strategies. CFIR was deemed to meet the needs of our project, as a determinant framework that can be used to identify determinants (i.e., barriers and facilitators) thought to affect the likelihood of a clinical guideline being translated into routine care and influence the implementation process at different levels (from the user to the program provider, to the organizational level) [33]. In Figure 1, we delineate the possible influencing factors for syncope clinical practice guideline (CPG) adoption and implementation through multi-stakeholder effort. The effectiveness of a multicomponent, multilevel implementation strategy will be mediated by the fidelity with which the intervention is delivered, and patient outcomes will be moderated by several patient-level factors. The entire process occurs within a context composed of system-level, organizational-level, and provider-level factors known to influence the implementation of a CPG [34].

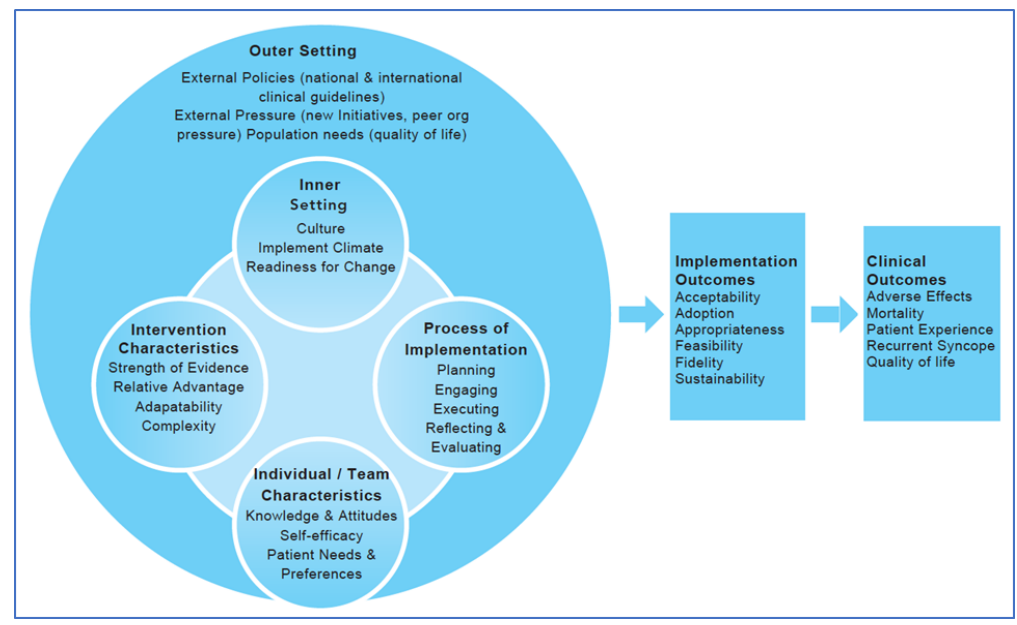

Figure 1. Project MISSION Guiding Framework, adapted from CFIR [32].

\subsection{Development of Implementation Strategy (MISSION)}

Table 1 delineates the influencing factors for syncope CPG adoption and implementation and lists the activities performed to assess determinants. The study team partnered with patients, family caregivers, frontline clinicians and staff, and administrators to assess contextual factors (e.g., patient preferences and needs, clinician perceptions, local organizational structure, operating philosophy and culture) and readiness for syncope guideline implementation. We conducted focus groups and interviews of patients and their family caregivers, clinicians and staff, and administrators $[35,36]$. We also surveyed clinicians and staff to understand unique challenges and barriers in each of these systems. The implementation questions addressed: (1) what are the facilitators/barriers to deliver- 
ing guideline-based evaluation and management of syncope within the local context, (2) how likely will the recommendations be delivered as prescribed (fidelity), and (3) what strategies might maximize the facilitators and overcome barriers to implementation? After completing context assessments, identifying barriers and facilitators, and soliciting stakeholders' inputs on strategies, we used the CFIR-ERIC (the Expert Recommendations for Implementing Change compilation) Implementation Strategy Matching Tool [37] to help select and tailor MISSION components to mitigate barriers and leverage facilitators.

Table 1. Study activities to assess barriers and facilitators.

\begin{tabular}{|c|c|c|}
\hline Domain & Construct & Assessment \\
\hline \multirow[t]{2}{*}{ Inner Setting } & Readiness for implementation & $\begin{array}{l}\text { 1. Survey-Organizational Readiness to Change } \\
\text { Assessment (ORCA) } \\
\text { 2. Focus groups and key informant } \\
\text { interviews—clinicians and stakeholders }\end{array}$ \\
\hline & $\begin{array}{l}\text { Structural characteristics (e.g., availability } \\
\text { of electronic information infrastructure) }\end{array}$ & $\begin{array}{l}\text { Focus groups and key informant } \\
\text { interviews-clinicians and stakeholders }\end{array}$ \\
\hline \multirow[b]{2}{*}{ Individual Characteristics } & Patient needs, values, and preferences & Focus groups-patients and family caregivers \\
\hline & $\begin{array}{l}\text { Provider attitudes to evidence-based } \\
\text { practices }\end{array}$ & $\begin{array}{l}\text { Survey-revised Evidence-Based Practice Attitudes } \\
\text { Scale (EBPAS-36) }\end{array}$ \\
\hline Intervention Characteristics & $\begin{array}{l}\text { Strength of evidence, relative advantage, } \\
\text { adaptability, and complexity }\end{array}$ & $\begin{array}{l}\text { Focus groups and key informant } \\
\text { interviews-clinicians and stakeholders }\end{array}$ \\
\hline
\end{tabular}

\subsection{Analysis}

Descriptive statistics were calculated for each survey item. Bivariate analyses were used to assess associations between characteristics (clinician specialty, hospital setting) and attitudes and readiness among respondents. Data were analyzed using SAS 9.4 (SAS Institute, Cary, NC, USA).

The interviews were transcribed verbatim for content analysis. The study team developed initial code books based on their clinical and implementation expertise. Coding took place in two stages. During the first stage, two research staff coders independently reviewed the transcripts to identify unique themes using NVivo 12 software (QSR International, Melbourne, Australia). After the first round of coding, both coders met to discuss any disagreements and refine the schema of codes and to refine the codebook for additional rounds of coding. Then, two coders met with the study team's qualitative expert to discuss and refine the coding schema by merging, reformulating, or rephrasing codes to more accurately fit the data and create one cohesive codebook. The two original coders then co-coded each transcript. Analytical memos were created and discussed as a group over a series of weekly meetings with the goal of refining and finalizing themes and categories.

This study was approved by the University of Kentucky Institutional Review Board (protocol \#45255).

\section{Results}

\subsection{Clinician Survey and Interview}

Project MISSION achieved broad engagement across multiple practice settings. One hundred fourteen clinicians completed surveys and thirty-two clinicians and stakeholders participated in interviews [22,35]. The survey and interview results have been reported in detail elsewhere [22,35]. Briefly, among clinicians, awareness and implementation of the 2017 Syncope Guideline was low. We identified practice gaps in under-reporting of orthostatic vital signs and overuse of cardiac and neurologic imaging, as well as barriers to adoption and implementation of evidence-based care across multiple levels. Survey results revealed that overall attitude toward evidence-based practices was moderate, and implementation of new guidelines were seen as a burden, potentially decreasing the likelihood of compliance. Of the multiple patient, provider, and organization-related 
barriers to syncope guideline implementation, we identified communication challenges with patients, lack of CPG protocol integration into ED workflows, and organizational process to change as major barriers to implement CPGs in syncope care [35].

\subsection{Patient and Family Caregiver Focus Group}

Project MISSION focus group sessions were conducted to understand patient needs, values and preferences. A total of 31 patients and their family caregivers, 23 patients and 8 caregivers, participated in interviews [36]. They described their expectations when presenting to the ED with syncope including: (1) clarity regarding their diagnosis or cause of their syncope, (2) context surrounding care plan and care teams' approach to diagnostic testing, and (3) desire to feel seen, heard and cared about by the healthcare team.

\subsection{Implementation Barrier-Strategy Mapping}

The findings from quantitative surveys and qualitative interviews helped guide decisions about the types of strategies that may be appropriate and match the needs of the local context. Based on the CFIR-ERIC Implementation Strategy Matching Tool (www.cfirguide.org (accessed on 20 March 2021)), we elicited input from the study team, frontline clinicians and staff, and administrators on choosing which ERIC strategies would best address specific CFIR-based barriers in guideline recommended syncope evaluation and management. Table 2 lists the identified CFIR barriers and ERIC recommended strategies.

Table 2. Syncope Clinical Practice Guideline (CPG) implementation barriers and recommended strategies.

\begin{tabular}{|c|c|}
\hline Identified CFIR Barriers & ERIC-Endorsed, MISSION Stakeholder-Recommended Strategies \\
\hline $\begin{array}{l}\text { Intervention-Complexity } \\
\text { Clinicians and stakeholders believe that the syncope } \\
\text { CPG is complex based on their perception of duration, } \\
\text { scope, disruptiveness, and number of steps needed to } \\
\text { implement. }\end{array}$ & $\begin{array}{l}\text { - } \quad \text { Promote adaptability } \\
\text { - } \quad \text { Develop an implementation toolkit } \\
\text { - } \quad \text { Conduct cyclical small tests of change } \\
\text { - } \quad \text { Conduct ongoing training }\end{array}$ \\
\hline $\begin{array}{l}\text { Outer Setting-Patient Needs } \\
\text { Clinicians feel the pressure to satisfy patients (i.e., } \\
\text { consumerism). } \\
\text { Patient needs are not known or fully understood by } \\
\text { clinicians. }\end{array}$ & $\begin{array}{l}\text { - } \quad \text { Prepare patients to be active participants } \\
\text { - } \quad \text { Involve patients and family caregivers } \\
\text { - } \quad \text { Equip clinicians with tools to help communication }\end{array}$ \\
\hline $\begin{array}{l}\text { Inner Setting-Culture and Learning Climate } \\
\text { Cultural norms and basic assumptions hinder } \\
\text { implementation. } \\
\text { Clinicians do not feel that they are essential, valued, and } \\
\text { knowledgeable partners in the implementation process. } \\
\text { Clinicians do not feel psychologically safe to implement } \\
\text { guidelines. }\end{array}$ & $\begin{array}{ll}\text { - } & \text { Facilitation by external agent/adviser } \\
\text { - } & \text { Identify and prepare champions } \\
\text { - } & \text { Identify and prepare core implementation team } \\
\text { - } & \text { Recruit, designate and train for leadership } \\
\text { - } & \text { Conduct local consensus discussions } \\
\text { - } & \text { Organize clinician implementation team meetings }\end{array}$ \\
\hline $\begin{array}{l}\text { Inner Setting-Compatibility } \\
\text { The syncope CPG recommendations do not fit well with } \\
\text { existing workflows, nor align well with clinicians' own } \\
\text { needs. }\end{array}$ & $\begin{array}{ll}\text { - } & \text { Conduct local consensus discussions } \\
\text { - } & \text { Promote adaptability } \\
\text { - } & \text { Tailor strategies } \\
\text { - } & \text { Lean QI methods }\end{array}$ \\
\hline $\begin{array}{l}\text { Individuals-Knowledge \& Beliefs about the Intervention } \\
\text { Clinicians are not familiar with } 2017 \text { Syncope Guideline. } \\
\text { Some clinicians have negative attitudes toward } \\
\text { guidelines and place low value on implementing them. }\end{array}$ & $\begin{array}{ll}\text { - } & \text { Conduct educational meetings } \\
\text { - } & \text { Develop educational materials } \\
\text { - } & \text { Conduct educational outreach visits } \\
\text { - } & \text { Identify and prepare champions } \\
\text { - } & \text { Inform local opinion leaders }\end{array}$ \\
\hline $\begin{array}{l}\text { Individuals-Self-efficacy } \\
\text { Clinicians and stakeholders do not have confidence in } \\
\text { their capabilities to execute courses of action to } \\
\text { achieve implementation goals. }\end{array}$ & $\begin{array}{ll}\text { - } & \text { Identify and prepare champions } \\
\text { - } & \text { Provide ongoing consultation } \\
\text { - } & \text { Conduct ongoing training } \\
\text { - } & \text { Make training dynamic }\end{array}$ \\
\hline
\end{tabular}




\subsection{MISSION Implementation Strategy Components}

After assessing and understanding determinants within the local context and identifying change methods to address those determinants, the last step was to develop strategy components to address the determinants considering how barriers interact with syncope care-specific needs. This process was also complemented with Fernandez and colleagues' five-step Implementation Process [38] and iterative feedback from stakeholders to further operationalize these components. Table 3 shows the multicomponent, multilevel implementation strategy (i.e., MISSION) components and expected functions/outcomes achieved.

Table 3. MISSION components.

\begin{tabular}{|c|c|}
\hline MISSION Components & Expected Functions/Outcomes \\
\hline $\begin{array}{l}\text { Patient educational materials } \\
\text { Video: Setting Expectations; What's Next? } \\
\text { Syncope Types: one-page document facilitating } \\
\text { clinician-patient communication }\end{array}$ & $\begin{array}{l}\text { - } \quad \text { Prepare patients and family caregivers } \\
\text { - } \quad \text { Assist clinician with challenging communications }\end{array}$ \\
\hline $\begin{array}{l}\text { External implementation mentor } \\
\text { Pre-implementation planning visit } \\
\text { Series of ten monthly virtual meetings with local } \\
\text { implementation team, including champion, implementation } \\
\text { leader and opinion leaders } \\
\text { Mid-implementation visit } \\
\text { Technical assistance with Lean QI methods }\end{array}$ & $\begin{array}{l}\text { - Create or Enhance culture of learning health systems and } \\
\text { continuous improvement } \\
\text { Enhanced leadership engagement in and endorsement of } \\
\text { CPG implementation in syncope care } \\
\text { - } \quad \text { Enhanced self-efficacy of local implementation team } \\
\text { Knowledge and skill transfer to local team and local } \\
\text { implementation capacity building }\end{array}$ \\
\hline $\begin{array}{l}\text { Academic detailing } \\
\text { Direct educational outreach to local clinicians } \\
\text { Clinical vignettes } \\
\text { Discussion with clinicians in their practice setting }\end{array}$ & $\begin{array}{l}\text { - } \quad \text { Clinician attitude and behavior changes } \\
\text { - Adherence to syncope CPGs and improvements in patient } \\
\text { outcomes }\end{array}$ \\
\hline Syncope Optimal Care Protocol & $\begin{array}{l}\text { - } \quad \text { Frontline-endorsed protocol as institutional policy } \\
\text { Enhanced clinician receptivity to standardized clinical } \\
\text { pathway with flexibility }\end{array}$ \\
\hline Syncope MISSION App [39] (iOS and Android) & $\begin{array}{ll}\text { - } & \text { Operationalized Syncope Optimal Care Protocol } \\
\text { - } & \text { Enhanced clinical decision support }\end{array}$ \\
\hline Lean QI methods & $\begin{array}{l}\text { - } \quad \text { Redesigned/optimized care process/workflow at ED with } \\
\text { syncope CPGs integrated }\end{array}$ \\
\hline Syncope MISSION Implementation Tool & - $\quad$ Operationalized implementation processes \\
\hline
\end{tabular}

Syncope patients see testing as a means to achieve clarity on their otherwise ambiguous condition. Clinicians can focus on two-way communication by engaging in active listening, obtaining a complete patient history, and explaining the rationale for or against various testing options. Printed educational materials are one of the most common forms of communicating guidelines. Our team developed educational videos (intake and discharge videos) to help align patient expectations regarding testing to fit with guideline recommendations, as well as tailored patient educational materials to better explain their specific syncope diagnosis. The Hospital Patient Education Department and the Patient and Family Advisory Group reviewed all educational materials, providing feedback and editing the materials to ensure an appropriate reading level. Additionally, we created a discharge document incorporating principles of adult learning theory and health literacy to help providers educate patients on the details of their diagnosis, preventive measures, and instructions to follow at the time of discharge.

In addition to clinical decision support (CDS) tools, the strategies aiming to promote clinician behavior change and optimize clinical process include mentored implementation combined with academic detailing. Mentored implementation provides external expert facilitation to enable and support health systems to make and sustain change, and efficiently integrate efforts into current workflow. It also facilitates active stakeholder engagement, 
offers ongoing support, and equips local champions for sustainability. This approach is proven to enhance adoption and implementation of evidence-based programs and innovations [40,41]. Academic detailing [42-44] is peer-to-peer educational outreach and addresses situations where there is an opportunity to change clinician behavior with focused and practical educational content. It can also help build leadership's buy-in to the proposed practice changes and help them understand how they can help the frontline implement these changes.

Project MISSION also created implementation strategies that address the process of integrating essential content from syncope CPGs to the local practice context and workflow. Clinical protocols provide specific guidance for management of groups of patients, in an algorithmic structure that facilitates clinical decision-making, tailored to the local environment. With input from diverse health systems and engagement of interdisciplinary expertise, our study team developed the Syncope Optimal Care Protocol based on the 2017 Guideline. The Syncope Optimal Care Protocol provides a standardized clinical pathway that has flexibility to make it more attractive to clinicians and aids in reducing variability, while improving quality and lowering cost. Next, a MISSION mobile application (App) was designed to be a practical tool for the implementation of the Syncope Optimal Care Protocol and serve as a CDS tool for syncope diagnosis and prognosis that walks users through clinical assessment in a clear and concise manner, and provides recommendations based on input from the user [39].

Finally, to address workflow compatibility and care process redesign, Lean quality improvement (QI) [45] tools were selected to be part of the implementation strategies. Lean generally focuses on how a process is currently operating and what opportunities exist to improve the process in a local setting, and therefore is a best practice in tailoring implementation. Application of Lean QI methods and tools aims to increase the likelihood of sustaining the daily practice and maximizing its impact in each health system.

\subsection{MISSION Implementation Strategy Pilot}

The Project MISSION implementation strategy was piloted from 17 Feb through 13 March 2020 at an AMC ED. The pilot stopped earlier than scheduled due to COVID-19, but demonstrated feasibility and acceptability, with $91.7 \%(22 / 24)$ of approached patients watching education videos with voiced approval, and 34 clinicians downloading and using the MISSION App. The 2017 Syncope Guidelines recommends that orthostatic vital signs, a low-cost, effective diagnostic test, are included as a required part of the physical examination for patients presenting with syncope. However, according to recent literature [46] and data reported by hospitals in this study, orthostatic vitals were underused, being performed on only $15 \%$ to $40 \%$ of patients. Routine head CT scan without a severe coexisting injury or disease is not recommended in the 2017 Syncope Guideline. A 2019 systematic review showed that more than half of patients with syncope underwent head CT scan at ED, but with a diagnostic yield of only $1.1 \%$ to $3.8 \%$ [47]. Based on the literature and stakeholders' recommendations, orthostatic vital signs and head CT orders are two major implementation outcome measures in our study. Given the low baseline, a relative 50\% increase in orthostatic vital signs will be considered as clinically significant, and given the high baseline, a relative $20 \%$ reduction in head CT scan orders will be clinically significant. Following MISSION implementation, we found that orthostatic vital sign measurement increased from $29 \%$ to $43 \%\left(\chi^{2}\right.$ statistic $=4.2664, p$-value $\left.=0.0389\right)$ and inappropriate head CT orders reduced from $48 \%$ to $37 \%\left(\chi^{2}\right.$ statistic $=2.3641, p$-value $\left.=0.1242\right)$. This demonstrated a clinically significant improvement in implementing CPGs in the evaluation and management of syncope.

\section{Discussion}

\subsection{Evaluation of Barriers Is a Necessity in Planning CPGs Implementation}

Despite substantial efforts by medical researchers and professional societies $[15,48,49]$, overuse and inappropriate use of testing and hospital admission are common in patients 
presenting with syncope. The most efficient solution to improve patient outcomes is most likely to adopt standardized criteria for evaluation and treatment administration based on the recommendations contained in guidelines. However, the uneven implementation of evidence-based CPGs is widely recognized as a continuing challenge to improving healthcare delivery and public health $[50,51]$. Implementation science provides an empirical base for promoting adoption of CPGs and its research is dedicated to accelerating the pace of implementing evidence-based interventions in real-world healthcare settings. What determines the rate and extent of adoption is the interaction among characteristics of the CPG, the intended users, and a particular context of care setting. As part of the clinical guideline implementation planning process, a more detailed evaluation of underlying barriers and facilitators and how these determinants can be addressed by strategies is needed.

\subsection{Local Context Tailored Implementation Strategy Is Essential}

While tailoring to local context seems intuitive, most studies have not tailored implementation strategies to context. Healthcare delivery settings influence every step of how care is given, yet far more work is needed to effectively describe and link these structural and process characteristics to outcomes and to develop setting-changing interventions to improve care. Numerous conceptual frameworks (e.g., CFIR) have been developed to guide the identification and systematically assess potential determinants within local settings. Project MISSION was the first effort that specifically applied IS principles and methods to develop strategies and plan implementation processes to overcome multilevel barriers to deliver guideline-recommended, high-value care to patients presenting with syncope in the ED. It integrated behavioral interventions and healthcare process redesign, used stakeholder-engaged and local-context congruent approaches, and fostered a learning health system approach spanning an academic medical center and community hospitals. Development of MISSION ensured tailoring of implementation strategies in the local setting to accommodate variations and to sustain improved syncope care through tailored implementation. For example, patient educational videos can be edited by inserting a tailored intro and outro delivered by a recognizable, local clinician to enhance patient buy-in. In addition, the video can be presented in various ways based on each system's infrastructure: via its system-wide patient education platform (either standalone or part of electronic health record-EHR), through a QR code to play on patients' smartphones, or through an iPad in patient rooms. Another example, supported by an external implementation mentor, is that the local implementation team can use local detailed process maps to systematically identify process steps with opportunities, and test and refine strategies to increase guideline-recommended syncope care delivery through iterative test cycles.

Limitations to the project should be mentioned. While the organizational structure, hospital characteristics, and patient populations are diverse, the themes presented in this paper were generated based on the responses of participants located in the same state. Second, pilot data were limited due to COVID-19 research restrictions. A larger pilot and implementation will be launched in our state, as well as others, once hospitals move into post-pandemic operation.

Identifying a barrier is not sufficient to guide the choice of an implementation strategy. The causes of each barrier must be specified along with the desired outcome, and the specific methods or techniques must be identified and operationalized into concrete strategies to influence these determinants. A process akin to systematically identifying barriers, change methods for addressing them, and development or selection for specific strategies is essential in implementing CPGs. Unfortunately, this approach is not typically followed, leading to gaps in understanding which strategies work and why they produce their effects. Project MISSION represents an example that utilized CFIR to characterize contextual determinants of CPG use, analyzed those determinants systematically via a theoretical framework, identified specific behavior change targets, and then selected relevant implementation strategies. Pilot testing of MISSION demonstrated feasibility and acceptability among patients, frontline clinicians and staff, and administrators. Our next 
step is to determine whether MISSION is an effective, generalizable strategy in a pragmatic clinical trial across multiple health systems.

\section{Conclusions}

Effective multifaceted implementation strategies targeting individuals, teams, and healthcare systems should be employed to plan successful implementation and promote adherence to CPGs. MISSION, developed by following implementation science principles, can optimize syncope care and translate CPGs into widespread clinical practice.

Author Contributions: Conceptualization, J.L., M.V.W. and S.S.S.; methodology, J.L., M.V.W. and S.S.S.; validation, J.L., M.V.W., S.S.S., J.L., C.A.M. and V.G.; formal analysis, J.L.; writing—original draft preparation, J.L.; writing—review and editing, M.V.W., S.S.S., J.M.C., C.A.M., V.G.; supervision, J.L.; project administration, J.M.C., C.A.M.; funding acquisition, J.L., M.V.W. and S.S.S. All authors have read and agreed to the published version of the manuscript.

Funding: This research was funded by the National Heart, Lung, and Blood Institute through grant number 1U01HL143508-01 (J.L., M.V.W. and S.S.S.).

Institutional Review Board Statement: This study was conducted according to the guidelines of the Declaration of Helsinki, and approved by the Institutional Review Board of the University of Kentucky, protocol \# 45255 approved 22 June 2018.

Informed Consent Statement: Informed consent was obtained from all subjects involved in the study.

Data Availability Statement: Data available from the authors upon reasonable request.

Conflicts of Interest: The authors declare no conflict of interest.

\section{References}

1. Sun, B.C.; Emond, J.A.; Camargo, C.A., Jr. Characteristics and admission patterns of patients presenting with syncope to US emergency departments, 1992-2000. Acad. Emerg. Med. 2004, 11, 1029-1034. [CrossRef]

2. Moya, A.; Sutton, R.; Ammirati, F.; Blanc, J.-J; Brignole, M.; Dahm, J.B.; Deharo, J.-C.; Gajek, J.; Gjesdal, K.; Krahn, A. Guidelines: Guidelines for the diagnosis and management of syncope (version 2009): The Task Force for the Diagnosis and Management of Syncope of the European Society of Cardiology (ESC). Eur. Heart J. 2009, 30, 2631.

3. Soteriades, E.S.; Evans, J.C.; Larson, M.G.; Chen, M.H.; Chen, L.; Benjamin, E.J.; Levy, D. Incidence and prognosis of syncope. N. Engl. J. Med. 2002, 347, 878-885. [CrossRef] [PubMed]

4. Costantino, G.; Sun, B.C.; Barbic, F.; Bossi, I.; Casazza, G.; Dipaola, F.; McDermott, D.; Quinn, J.; Reed, M.J.; Sheldon, R.S.; et al. Syncope clinical management in the emergency department: A consensus from the first international workshop on syncope risk stratification in the emergency department. Eur. Heart J. 2016, 37, 1493-1498. [CrossRef] [PubMed]

5. Rui, P.; Kang, K.; Albert, M. National Hospital Ambulatory Medical Care Survey: 2014 Emergency Department Summary Tables; Centers for Disease Control and Prevention: Washington, DC, USA. Available online: https://www.cdc.gov/nchs/data/nhamcs/web_ tables /2017_ed_web_tables-508.pdf (accessed on 15 February 2018).

6. Shen, W.K.; Decker, W.W.; Smars, P.A.; Goyal, D.G.; Walker, A.E.; Hodge, D.O.; Trusty, J.M.; Brekke, K.M.; Jahangir, A.; Brady, P.A.; et al. Syncope Evaluation in the Emergency Department Study (SEEDS): A multidisciplinary approach to syncope management. Circulation 2004, 110, 3636-3645. [CrossRef] [PubMed]

7. D'Ascenzo, F.; Corleto, A.; Biondi-Zoccai, G.; Anselmino, M.; Ferraris, F.; di Biase, L.; Natale, A.; Hunter, R.J.; Schilling, R.J.; Miyazaki, S.; et al. Which are the most reliable predictors of recurrence of atrial fibrillation after transcatheter ablation?: A meta-analysis. Int. J. Cardiol. 2013, 167, 1984-1989. [CrossRef]

8. Anderson, J.B.; Czosek, R.J.; Knilans, T.K.; Marino, B.S. The effect of paediatric syncope on health-related quality of life. Cardiol. Young 2012, 22, 583-588. [CrossRef]

9. Giada, F.; Silvestri, I.; Rossillo, A.; Nicotera, P.G.; Manzillo, G.F.; Raviele, A. Psychiatric profile, quality of life and risk of syncopal recurrence in patients with tilt-induced vasovagal syncope. Europace 2005, 7, 465-471. [CrossRef] [PubMed]

10. Linzer, M.; Pontinen, M.; Gold, D.T.; Divine, G.W.; Felder, A.; Brooks, W.B. Impairment of physical and psychosocial function in recurrent syncope. J. Clin. Epidemiol. 1991, 44, 1037-1043. [CrossRef]

11. Rose, M.S.; Koshman, M.L.; Ritchie, D.; Sheldon, R. The development and preliminary validation of a scale measuring the impact of syncope on quality of life. Europace 2009, 11, 1369-1374. [CrossRef]

12. Santhouse, J.; Carrier, C.; Arya, S.; Fowler, H.; Duncan, S. A comparison of self-reported quality of life between patients with epilepsy and neurocardiogenic syncope. Epilepsia 2007, 48, 1019-1022. [CrossRef] [PubMed]

13. Faddis, M.N.; Rich, M.W. Pacing interventions for falls and syncope in the elderly. Clin. Geriatr. Med. 2002, 18, 279-294. [CrossRef]

14. Forman, D.E.; Rich, M.W.; Alexander, K.P.; Zieman, S.; Maurer, M.S.; Najjar, S.S.; Cleveland, J.C., Jr; Krumholz, H.M.; Wenger, N.K. Cardiac care for older adults. Time for a new paradigm. J. Am. Coll. Cardiol. 2011, 57, 1801-1810. [CrossRef] [PubMed] 
15. Shen, W.-K.; Sheldon, R.S.; Benditt, D.G.; Cohen, M.I.; Forman, D.E.; Goldberger, Z.D.; Grubb, B.P.; Hamdan, M.H.; Krahn, A.D.; Link, M.S. 2017 ACC/AHA/HRS guideline for the evaluation and management of patients with syncope: A report of the American College of Cardiology/American Heart Association Task Force on Clinical Practice Guidelines and the Heart Rhythm Society. J. Am. Coll. Cardiol. 2017, 70, e39-e110. [CrossRef] [PubMed]

16. Joy, P.S.; Kumar, G.; Olshansky, B. Syncope: Outcomes and conditions associated with hospitalization. Am. J. Med. 2017, 130, 699-706.e696. [CrossRef] [PubMed]

17. Probst, M.A.; Kanzaria, H.K.; Gbedemah, M.; Richardson, L.D.; Sun, B.C. National trends in resource utilization associated with ED visits for syncope. Am. J. Emerg. Med. 2015, 33, 998-1001. [CrossRef] [PubMed]

18. Huff, J.S.; Decker, W.W.; Quinn, J.V.; Perron, A.D.; Napoli, A.M.; Peeters, S.; Jagoda, A.S. Clinical policy: Critical issues in the evaluation and management of adult patients presenting to the emergency department with syncope. J. Emerg. Nurs. 2007, 33, e1-e17. [CrossRef] [PubMed]

19. Canzoniero, J.V.; Afshar, E.; Hedian, H.; Koch, C.; Morgan, D.J. Unnecessary hospitalization and related harm for patients with low-risk syncope. JAMA Intern. Med. 2015, 175, 1065-1067. [CrossRef]

20. Thiruganasambandamoorthy, V.; Taljaard, M.; Stiell, I.G.; Sivilotti, M.L.; Murray, H.; Vaidyanathan, A.; Rowe, B.H.; Calder, L.A.; Lang, E.; McRae, A. Emergency department management of syncope: Need for standardization and improved risk stratification. Intern. Emerg. Med. 2015, 10, 619-627. [CrossRef] [PubMed]

21. Dipaola, F.; Costantino, G.; Perego, F.; Borella, M.; Galli, A.; Cantoni, G.; Barbic, F.; Casella, F.; Duca, P.G.; Furlan, R. San Francisco Syncope Rule, Osservatorio Epidemiologico sulla Sincope nel Lazio risk score, and clinical judgment in the assessment of short-term outcome of syncope. Am. J. Emerg. Med. 2010, 28, 432-439. [CrossRef]

22. Smyth, S.; Gupta, V.; Williams, M.; Cowley, A.; Sirrine, M.; Surratt, H.; Chadha, R.; Stearley, S.; Bhalla, V.; Li, J. Identifying guideline-practice gaps to optimize evaluation and management for patients with syncope. Can. J. Cardiol. 2020, 37, 500-503. [CrossRef]

23. Bero, L.A.; Grilli, R.; Grimshaw, J.M.; Harvey, E.; Oxman, A.D.; Thomson, M.A. Closing the gap between research and practice: An overview of systematic reviews of interventions to promote the implementation of research findings. BMJ 1998, 317, 465-468. [CrossRef] [PubMed]

24. Grimshaw, J.M.; Russell, I.T. Effect of clinical guidelines on medical practice: A systematic review of rigorous evaluations. Lancet Lond. 1993, 342, 1317-1322. [CrossRef]

25. Grol, R.; Grimshaw, J. From best evidence to best practice: Effective implementation of change in patients' care. Lancet 2003, 362, 1225-1230. [CrossRef]

26. Grol, R.; Wensing, M.; Eccles, M.; Davis, D. Improving Patient Care: The Implementation of Change in Health Care; John Wiley \& Sons: Hoboken, NJ, USA, 2013.

27. Lugtenberg, M.; Burgers, J.; Westert, G. Effects of evidence-based clinical practice guidelines on quality of care: A systematic review. BMJ Qual. Saf. 2009, 18, 385-392. [CrossRef]

28. Chou, S.-C.; Nagurney, J.M.; Weiner, S.G.; Hong, A.S.; Wharam, J.F. Trends in advanced imaging and hospitalization for emergency department syncope care before and after ACEP clinical policy. Am. J. Emerg. Med. 2019, 37, 1037-1043. [CrossRef]

29. Chambers, D.A.; Glasgow, R.E.; Stange, K.C. The dynamic sustainability framework: Addressing the paradox of sustainment amid ongoing change. Implement. Sci. 2013, 8, 117. [CrossRef]

30. Wensing, M. The Tailored Implementation in Chronic Diseases (TICD) project: Introduction and main findings. Implement. Sci. 2017, 12, 5. [CrossRef]

31. Baker, R.; Camosso-Stefinovic, J.; Gillies, C.; Shaw, E.J.; Cheater, F.; Flottorp, S.; Robertson, N.; Wensing, M.; Fiander, M.; Eccles, M.P. Tailored interventions to address determinants of practice. Cochrane Database Syst. Rev. 2015. [CrossRef] [PubMed]

32. Damschroder, L.J.; Aron, D.C.; Keith, R.E.; Kirsh, S.R.; Alexander, J.A.; Lowery, J.C. Fostering implementation of health services research findings into practice: A consolidated framework for advancing implementation science. Implement Sci. 2009, 4, 50. [CrossRef]

33. Nilsen, P. Making sense of implementation theories, models and frameworks. Implement Sci 2015, 10, 53. [CrossRef]

34. Brownson, R.C.; Colditz, G.A.; Proctor, E.K. Dissemination and Implementation Research in Health: Translating Science to Practice; Oxford University Press: Oxford, UK; New York, NY, USA, 2012; p. xxiii, 536p.

35. Li, J.; Gupta, V.; Smyth, S.S.; Cowley, A.; Du, G.; Sirrine, M.; Stearley, S.; Chadha, R.; Bhalla, V.; Williams, M. Value-based syncope evaluation and management: Perspectives of health care professionals on readiness, barriers and enablers. Am. J. Emerg. Med. 2020, 38, 1867-1874. [CrossRef]

36. Clouser, J.; Sirrine, M.; McMullen, C.; Cowley, A.; Smyth, S.; Gupta, V.; Williams, M.V.; Li, J. Passing out is a serious thing: Patient expectations for syncope evaluation and management. Patient Prefer. Adherence 2021, in press.

37. Waltz, T.J.; Powell, B.J.; Fernández, M.E.; Abadie, B.; Damschroder, L.J. Choosing implementation strategies to address contextual barriers: Diversity in recommendations and future directions. Implement. Sci. 2019, 14, 1-15. [CrossRef] [PubMed]

38. Fernandez, M.E.; Ten Hoor, G.A.; van Lieshout, S.; Rodriguez, S.A.; Beidas, R.S.; Parcel, G.; Ruiter, R.A.; Markham, C.M.; Kok, G. Implementation mapping: Using intervention mapping to develop implementation strategies. Front. Public Health $2019,7,158$. [CrossRef]

39. Amin, S.G.V.; Du, G.; McMullen, C.; Sirrine, M.; Williams, M.V.; Smyth, S.S.; Chada, R.; Stearley, S.; Li, J. MISSION Syncope App: Developing An Evidence-based Clinical Support Tool. J. Med. Internet Res. 2020. [CrossRef] 
40. Williams, M.V.; Li, J.; Hansen, L.O.; Forth, V.; Budnitz, T.; Greenwald, J.L.; Howell, E.; Halasyamani, L.; Vidyarthi, A.; Coleman, E.A. Project BOOST implementation: Lessons learned. South Med. J. 2014, 107, 455-465. [CrossRef] [PubMed]

41. Li, J.; Hinami, K.; Hansen, L.O.; Maynard, G.; Budnitz, T.; Williams, M.V. The physician mentored implementation model: A promising quality improvement framework for health care change. Acad. Med. 2015, 90, 303-310. [CrossRef] [PubMed]

42. Soumerai, S.B.; Avorn, J. Principles of educational outreach ('academic detailing') to improve clinical decision making. JAMA 1990, 263, 549-556. [CrossRef]

43. O’Brien, M.A.; Rogers, S.; Jamtvedt, G.; Oxman, A.D.; Odgaard-Jensen, J.; Kristoffersen, D.T.; Forsetlund, L.; Bainbridge, D.; Freemantle, N.; Davis, D. Educational outreach visits: Effects on professional practice and health care outcomes. Cochrane Database Syst. Rev. 2007, 4. [CrossRef]

44. Van Hoof, T.J.; Harrison, L.G.; Miller, N.E.; Pappas, M.S.; Fischer, M.A. Characteristics of academic detailing: Results of a literature review. Am. Health Drug Benefits 2015, 8, 414. [PubMed]

45. Graban, M. Lean Hospitals: Improving Quality, Patient Safety, and Employee Engagement; CRC press: Boca Raton, FL, USA, 2016.

46. van Wijnen, V.K.; Gans, R.O.; Wieling, W.; Ter Maaten, J.C.; Harms, M.P. Diagnostic accuracy of evaluation of suspected syncope in the emergency department: Usual practice vs. ESC guidelines. BMC Emerg. Med. 2020, 20, 1-9. [CrossRef] [PubMed]

47. Viau, J.A.; Chaudry, H.; Hannigan, A.; Boutet, M.; Mukarram, M.; Thiruganasambandamoorthy, V. The yield of computed tomography of the head among patients presenting with syncope: A systematic review. Acad. Emerg. Med. 2019, 26, 479-490. [CrossRef] [PubMed]

48. Brignole, M.; Moya, A.; de Lange, F.J.; Deharo, J.C.; Elliott, P.M.; Fanciulli, A.; Fedorowski, A.; Furlan, R.; Kenny, R.A.; Martin, A.; et al. 2018 ESC Guidelines for the diagnosis and management of syncope. Eur. Heart J. 2018, 39, 1883-1948. [CrossRef]

49. Brignole, M.; Moya, A.; de Lange, F.J.; Deharo, J.C.; Elliott, P.M.; Fanciulli, A.; Fedorowski, A.; Furlan, R.; Kenny, R.A.; Martín, A.; et al. Practical Instructions for the 2018 ESC Guidelines for the diagnosis and management of syncope. Eur. Heart J. 2018, 39, e43-e80. [CrossRef] [PubMed]

50. Kruk, M.E.; Gage, A.D.; Arsenault, C.; Jordan, K.; Leslie, H.H.; Roder-DeWan, S.; Adeyi, O.; Barker, P.; Daelmans, B.; Doubova, S.V.; et al. High-quality health systems in the Sustainable Development Goals era: Time for a revolution. Lancet Glob Health 2018, 6, e1196-e1252. [CrossRef]

51. Correa, V.C.; Lugo-Agudelo, L.H.; Aguirre-Acevedo, D.C.; Contreras, J.A.P.; Borrero, A.M.P.; Patiño-Lugo, D.F.; Valencia, D.A.C. Individual, health system, and contextual barriers and facilitators for the implementation of clinical practice guidelines: A systematic metareview. Health Res. Policy Syst. 2020, 18, 74. [CrossRef] 